\title{
Mobile laparoscopy: use of the smartphone as a tool in the operating room
}

Keywords: single-port approach, robotic surgery, colorectal, gastric, hepatobiliary, bariatric surgery

Abbreviations: SILS, single-port approach; WHO, World Health Organization; ACR, absolute category rating

\section{Introduction}

Laparoscopic surgery also known as minimally invasive surgery has revolutionized the surgical field for the past 20years, it has gained popularity and acceptance among both surgeons and patients thanks to its advantages including postoperative pain reduction, early recovery, smaller incisions and shorter hospital stay. Recently there has been a staggering development of techniques, equipment and instruments; the technique has progressed from simple surgical procedures to advanced levels, so much that surgeons have been performing successfully more complex procedures and have recently introduced new modalities that are gaining wide popularity, such as robotic surgery and single-port approach (SILS). Many procedures that were previously considered contraindicated for laparoscopic approach are currently indicated and performed via laparoscopy in a standardized fashion such is the case in colorectal, gastric, hepatobiliary and bariatric surgery, among others, which is why it became one of the main tools used now by general surgeon worldwide. ${ }^{1,2}$

Technological innovation advances hastily and the availability of powerful devices at lower costs increases constantly. The global distribution and use of smartphones makes them a practical and promising technology in medicine. ${ }^{3,4}$ Each day there's an increasing number of technological developments and applications to be used on smartphones in order to improve and democratize healthcare; ${ }^{5}$ improvements and updates of portable devices are becoming more sophisticated and diverse ${ }^{6}$ Currently three quarters of the population has access to mobile phones, and only in Venezuela there are at least

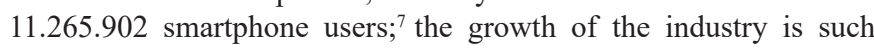
that it is estimated that by 2017 there will be more mobile phones than people in the world, ${ }^{8}$ which is why it can be considered that these devices play a critical role in many aspects of our lives. Among many benefits, smartphones have the capacity for global interconnectivity which makes them a practical and promising resource in the field of medical sciences, creating paths to improve the quality of health services, with the added benefit of lowering costs. ${ }^{9}$

In the last 5 years there has been an evident tendency to incorporate these technologies in different aspects of medicine (preventive, diagnostic and therapeutic) $)^{10,11}$ so much in fact that the World Health Organization acknowledged that mobile and wireless technology has the potential to transform the way healthcare is provided around the world and has established the term "electronic health" (eHealth) to define the use of information technologies and communication as a backup in the practice of health sciences, including the provision of services, health screening, access to medical literature, education and research. ${ }^{12}$ The term "mHealth" (mobile health) has emerged as a
Volume 10 Issue 5 - 2019

\author{
Pedro Monsalve, ' Gabriela Lombardo \\ Pascarelli,' Elaine J Bastardo Milano ${ }^{2}$ \\ 'Specialist Surgeon, Central University of Venezuela, Venezuela \\ ${ }^{2}$ Instructor Professor, Central University of Venezuela, Venezuela
}

Correspondence: Elaine J Bastardo Milano, Instructor professor. Universidad Central de Venezuela. Active Member SVC,Venezuela, Email elainebm05@gmail.com

Received: September 21, 2019 | Published: October 31, 2019

subdivision of the eHealth, and it's used to define medical and public health practice supported specifically by the use of mobile devices and smartphones, tablets and PDAs. MHealth is currently pushing the limits of how doctors acquire, transport, store, process and share information in order to provide useful results, so much in fact that medical applications are now a point of encounter between many healthcare profesionals. ${ }^{13}$

Modern endoscopy has become a necessary tool for diagnosis and treatment in many clinical specialties: thoracic surgery, gastroenterology, urology and coloproctology to mention some. ${ }^{14,15}$ Due to advances in technology of conventional flexible endoscopy such as smaller endoscopes, LEDs and miniaturization of the camera, these procedures have been transferred from the operating room to the consult, and although it is undoubtable that the quality of traditional equipment has been improved in all respects, unlike mobile technology (laptops, tablets and smartphones), the cost of endoscopes and their essential accessories (light source, monitor, HD cameras) is steadily rising, ${ }^{16}$ therefore restricting the use of these major technologies in most health centers.

Currently all smartphones have HD cameras; by aligning this camera with a $32 \mathrm{~mm}$ scope, a sharp image can be captured and the autofocus and aperture mechanisms used by the smartphone camera allow the digital reconstruction of the image in HD display of the device, ${ }^{17}$ allowing thus the use of its primary display or the use of a secondary monitor while the procedure is simultaneously recorded. The volume of the data of this videos can be lowered significantly immediately after it has been recorded, with little loss in the quality of audio/video ${ }^{18}$ so that the information can be sent via mail or instant messaging applications providing thus documentation and allowing the possibility for teleconsultation, ${ }^{19}$ particularly in situations involving decisions based on findings where it is critical to have specific visual cues in order to provide an accurate diagnosis. ${ }^{20}$

The key element to yield a device with these characteristics is an adjustable base that secures the $32 \mathrm{~mm}$ scope without causing movement prevents filtration of ambient light and does not compromise 
the quality of the image. This article describes an assembly system that transforms a smartphone into a portable endoscopic mobile unit and it's compared to a conventional endoscopic device.

\section{Materials and methods}

The work here presented is a comparative, simply blinded, experimental study.

\section{Adaptation of portable laparoscopic device}

The aim of the device is to temporarily secure in a stable manner the smartphone through a base (Figure 1) with adjustable clamps that in turn allow the coupling of a $32 \mathrm{~mm}$ scope through a safety ring that applies uniform radial pressure around the circumference of such optical piece, converting thus the ensemble in an operative, portable endoscope. The base as a whole was assembled using commercially available components and accessories handcrafted for this study in order to transmit the image of a laparoscopic optic to a portable phone (Apple Iphone 6S, Apple Inc, Cupertino CA) in camera mode, with which we obtained a combined image with an effective focal length of approximately $18 \mathrm{~mm}$. This configuration was tested with a laparoscopic scope Gimmi Alphascope II ø $2,7 \mathrm{~mm} 30^{\circ}$, resulting in a centered image created entirely on the camera lens system and the mobile device. The difference in the size of the image is compensated by the digital zoom that allows filling the whole of the screen with an image of high definition of excellent quality. For the light source, we used a 10W LED flashlight of commercial use with a color temperature of $9.500 \mathrm{~K}, 140 \mathrm{Lx}$ illumination, 45-degree operating temperature and it was adapted to connect to the input of any Olympus/Storz scope (Figure 2).

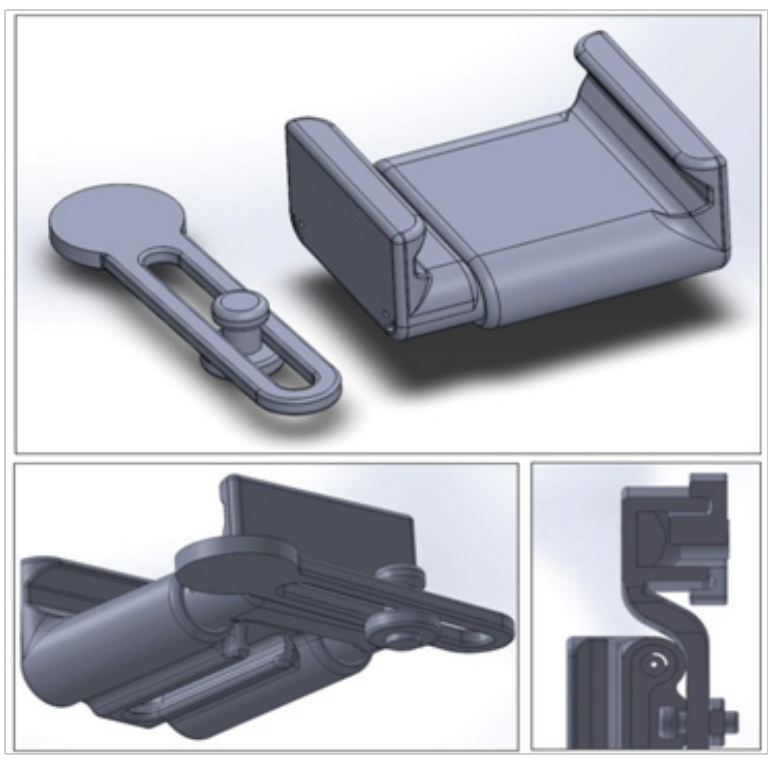

Figure I Acrylic base to couple smart phone.

In addition to the handset display, the operating system of these platforms (iOS, Android) allows the user to mirror the image simultaneously to a secondary monitor either through an adapter cable or wirelessly (Airplay, Apple TV). The secondary monitor can be a monitor of any size with an HDMI adapter, placed in the same operating room or endoscopy room (Figure 3).
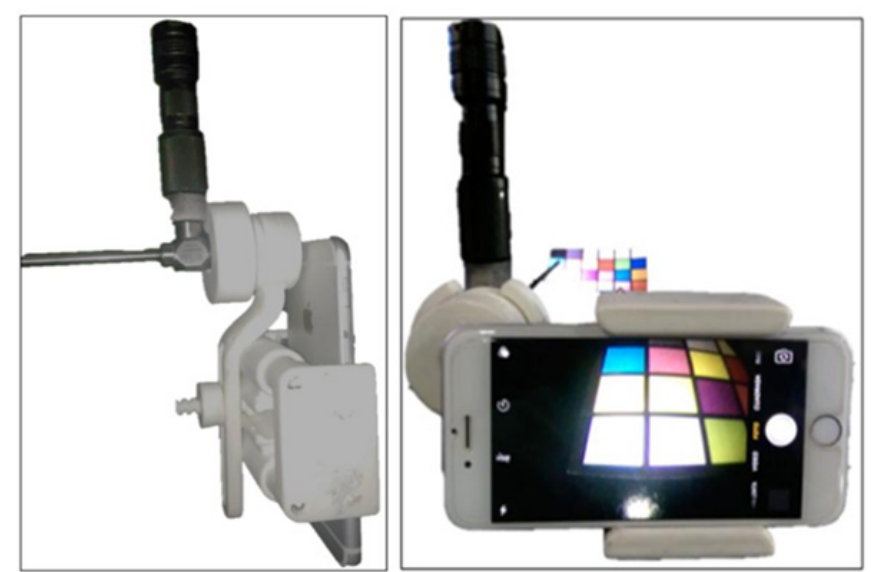

Figure 2 Smartphone coupled to acrylic base, light source (lantern) and

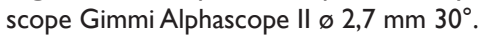

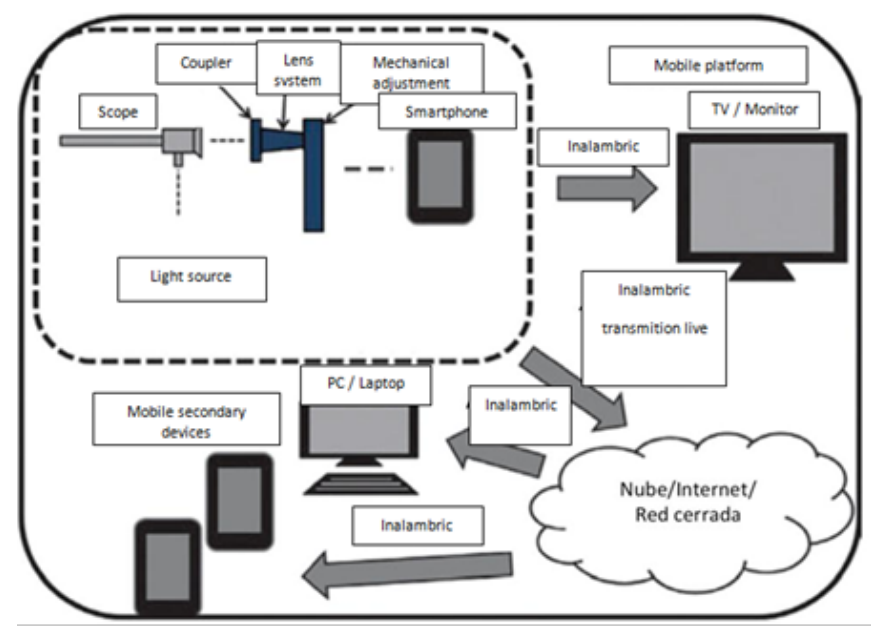

Figure 3 Assembly process smart phone - scope- base - video devices.

\section{Determination of image quality}

The videos produced were obtained from two sources: first from the portable device coupled to the smartphone and a second one from a conventional endoscopic camera (Olympus CV-180 Evis Video System Exera II coupled to Gimmi Alphascope II Camera $\varnothing 2,7 \mathrm{~mm} 30^{\circ}$ ). In order to standardize the resolution of the image, the United States Air Force resolution test card (Edmund Industrial Optics, Barrington, NJ) was used to group vertical and horizontal lines in different measurements and the resolution was calculated as the smallest group of elements than can be clearly visualized (lines/ $\mathrm{mm}$ ); this chart is most often used as a reference for testing the quality of many optical devices (microscopes, cameras and scanners). ${ }^{21}$ The color on the other hand was standardized through a Munsell color system which organizes color according to hue, lightness and saturation and it is widely used for the study of optical devices as well. ${ }^{22}$ The colors compared between the two devices were red, orange, yellow, green, blue and violet (Figures $4 \& 5$, respectively).

The optics were separated $1 \mathrm{~cm}$ away from the cards and the images were recorded on both devices making the same movements and orientation changes. The lighting in the case of the conventional 
laparoscopic tower was given by the source included in the tower (300W Xenon lamp). Both recordings were edited with iMovie 2016 video editing software (version 10.1.2) to produce two final and identical videos of 20 seconds each where the elements meant to be evaluated are clearly evident, it's important to clarify that there was no manipulation of the image or any filters or additional effects were used.

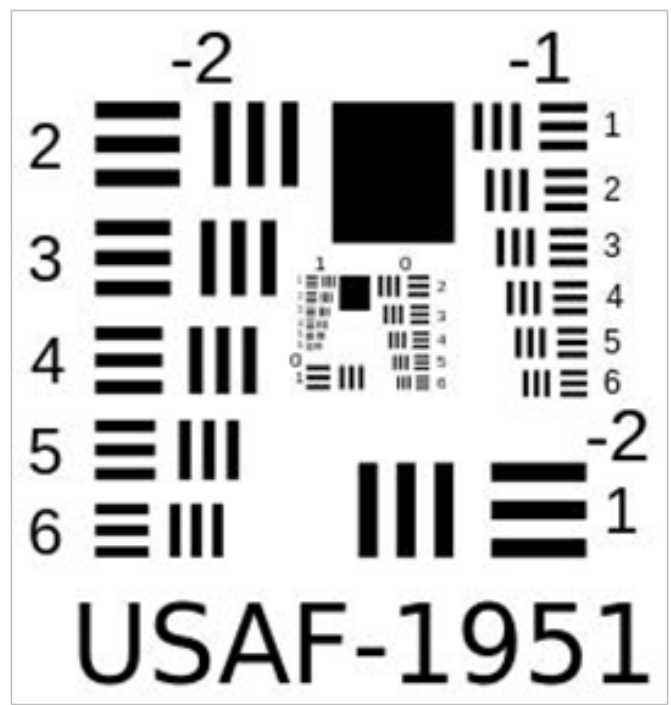

Figure 4 195I USAF resolution test chart.

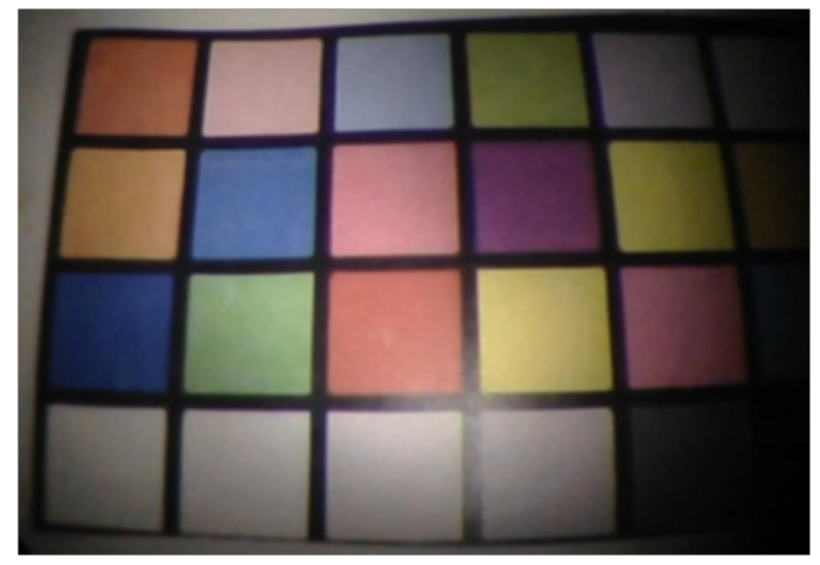

Figure 5 Munsel color chart.

For the aim of this study we chose subjective measures of different aspects to establish a general level of satisfaction with the image shown, it's nonetheless critical to take into account some elements: 1) The main limiting factor to objectively measure the quality of an image rather than the recording device is given by the optics used;2) it has already been shown that differences in image resolution, color and image quality are not significant when comparing next generation mobile devices vs. conventional endoscopes; and 3) regardless of the technical elements of the image, some parameters such as image orientation can only be interpreted by the endoscopist surgeon performing the procedure. ${ }^{23,24}$

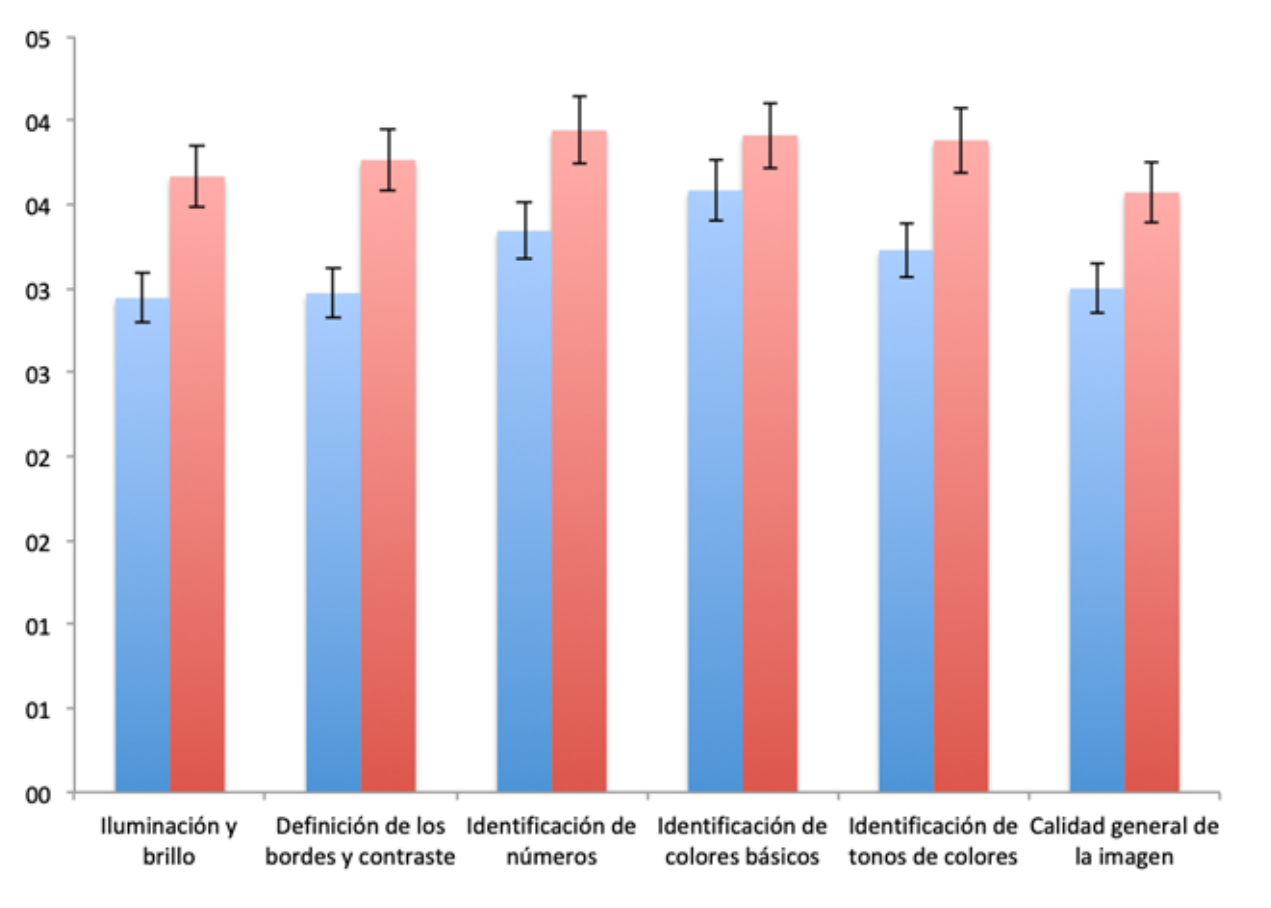

Graph I Comparison of averages by average.

Smartphone coupled device.

Laparoscope Olympus HD. 
The tool used to collect the data was the absolute category rating (ACR), which is a test method that has proven to be a reproducible system for evaluating the quality of videos, and consists of presenting both videos in a single session and qualify multiple variables independently using a scale of 5 levels ${ }^{25}$. The unidentified videos and the survey were sent by e-mail to 35 surgeons, members of the Venezuelan Society of Bariatric Surgery and experts in laparoscopy, for their observation and assessment by filling an online survey. The survey considered 6 categories rated from 1 to 5 , as follows:

\section{From the video, you just watched, evaluate the following items on a scale from I (poor) to 5 (excellent)}

1. How do you consider the lighting and the brightness of the image?

2. How do you consider the definition of the contrast and the edges of the images?

3. Could you identify the numbers in the picture?

4. Could you identify the basic colors in the image (yellow, blue, red, green and violet)?

5. Could you identify the different shades of the basic colors?

6. What would you consider to be the overall quality of the whole video?

Once the data was collected and recorded we proceeded to compare the average score in each question and the overall average statistics using Student's $t$-test with a confidence interval of 0.99 .

\section{Results}

After the evaluation of the videos by 35 surgeons belonging to the Venezuelan Society of Surgery and after answering the 6 questions for both videos provided before, the following results were obtained (Tables $1 \& 2$ ).

Table I Smartphone coupled device

\begin{tabular}{|c|c|c|c|c|}
\hline Question & & Average & Variance & $\begin{array}{l}\text { Standard } \\
\text { deviation }\end{array}$ \\
\hline I. & $\begin{array}{l}\text { How do } \\
\text { you con- } \\
\text { sider the } \\
\text { lighting and } \\
\text { the bright- } \\
\text { ness of the } \\
\text { image? }\end{array}$ & 2.9 & 0.64 & 0.8 \\
\hline 2. & $\begin{array}{l}\text { How do } \\
\text { you con- } \\
\text { sider the } \\
\text { definition of } \\
\text { the contrast } \\
\text { and the } \\
\text { edges of the } \\
\text { images? }\end{array}$ & 3.0 & 0.91 & 1.0 \\
\hline 3. & $\begin{array}{l}\text { Could you } \\
\text { identify the } \\
\text { numbers in } \\
\text { the picture? }\end{array}$ & 3.3 & 0.82 & 0.9 \\
\hline
\end{tabular}

Table Continued...

\begin{tabular}{|c|c|c|c|c|}
\hline Question & & Average & Variance & $\begin{array}{l}\text { Standard } \\
\text { deviation }\end{array}$ \\
\hline 4. & $\begin{array}{l}\text { Could you } \\
\text { identify the } \\
\text { basic colors } \\
\text { in the image } \\
\text { (yellow, } \\
\text { blue, red, } \\
\text { green and } \\
\text { purple)? }\end{array}$ & 3.6 & 0.76 & 0.9 \\
\hline 5. & $\begin{array}{l}\text { Could you } \\
\text { identify } \\
\text { the different } \\
\text { shades of } \\
\text { the basic } \\
\text { colors? }\end{array}$ & 3.2 & 0.65 & 0.8 \\
\hline 6. & $\begin{array}{l}\text { What } \\
\text { would you } \\
\text { consider } \\
\text { to be the } \\
\text { overall qua- } \\
\text { lity of the } \\
\text { whole video } \\
\text { to be? }\end{array}$ & 3.0 & 0.47 & 0.7 \\
\hline
\end{tabular}

Table 2 Olympus HD Conventional Laparoscope

Question Average Variance $\begin{aligned} & \text { Standard } \\ & \text { deviation }\end{aligned}$

I. How do you consider the lighting and the 3.87 0.85 brightness of the image to be?

2. How do you consider the definition of the contrast and 3.8 the edges of the images to be?

3. Could you identify the numbers in the picture?

4. Could you identify the basic colors in the image (yellow,

blue, red, green and purple)?

5. Could you identify the different shades of the basic colors?

6. What would you consider to be the overall quality of the whole $\begin{array}{ll}3.6 & 0.78\end{array}$ video to be? 
We were able to identify that the averages for each question was higher for the conventional High Definition laparoscope, but only a significant difference was obtained in the edge definition and contrast item of the images. It is worth noting that in the evaluation of the overall quality of the video, statistically both videos are of equal quality.

\section{Discussion}

After comparing the quality of the smartphone coupled to endoscopic camera vs HD laparoscope to check the feasibility of use in future procedures by establishing the image quality comparatively, we obtained that at the 6 items evaluated, it was verified that there was only a significant difference in the contrast and edges of the image (Table 3). In relation to the other items evaluated and even when assessing the overall quality of the video no significant differences were found between both groups, which allows us to assume that such adaptation can be easily used in surgical procedures in vivo. Similar results were obtained by Liu et al. ${ }^{26}$ who compared 30 videos for diagnosis of otorhinolaryngological conditions using a conventional otoscopy equipment with a smartphone adaptation as a video device similar to ours, and obtained excellent results and similar quality of images, sufficient for diagnosis of pathologies.

Table 3 Comparison of averages per question $\mathrm{p}=0.99$

\begin{tabular}{clll}
\hline Question & Average & Variance & P \\
\hline I. & $\begin{array}{l}\text { How do you consider } \\
\text { the lighting and the } \\
\text { brightness of the image } \\
\text { to be? }\end{array}$ & 2.9 & 3.8 \\
2. $\quad \begin{array}{l}\text { How do you consider } \\
\text { the definition of the } \\
\text { contrast and the edges } \\
\text { of the images to be? }\end{array}$ & 3.0 & 3.8 \\
3. $\quad \begin{array}{l}\text { Could you identify the } \\
\text { numbers in the picture? }\end{array}$ & 3.3 & 3.9 \\
4. $\begin{array}{l}\text { Could you identify the } \\
\text { basic colors in the image } \\
\text { (yellow, blue, red, green } \\
\text { and purple)? }\end{array}$ & 3.6 & 3.9 \\
5. $\begin{array}{l}\text { Could you identify } \\
\text { the different shades of } \\
\text { the basic colors? }\end{array}$ & 3.2 & 3.9 \\
6. $\begin{array}{l}\text { What would you con- } \\
\text { sider to be the overall } \\
\text { quality of the whole } \\
\text { video? }\end{array}$ & 3.0 & 3.6 \\
\hline
\end{tabular}

In the same fashion Sohn et al. ${ }^{27}$ compared the image resolution obtained with the use of Endoskope ${ }^{\circledR}$ (a docking system coupled to an Iphone5S) with a conventional laparoscopic device using both inanimate models and porcine cystoscopies without obtaining significant differences between the quality of the images but with a large difference in the cost of equipment acquisition (\$154 with Endoskope ${ }^{\circledR}$ and iPhone Vs $\$ 46,623$ of the standard HD endoscopic system). With the sizeable and swift improvement of video devices from smartphones, the potential for performing portable laparoscopes increases progressively. It is demonstrated that the image quality is similar and the cost is considerably lower.

\section{Conclusion}

We conclude that the smartphone coupled to an endoscopic camera as a video device for performing laparoscopy has a similar quality to a conventional laparoscopy HD device in vitro, wich would allow the following use of this system to perform laparoscopic procedures with a safe, secure and cost effectively device.

\section{Acknowledgments}

None.

\section{Conflicts of interest}

The authors declare there are no conflicts of interest related to the article.

\section{Funding}

None.

\section{References}

1. Sauerland S, Jaschinski T, Neugebauer EAM. Laparoscopic versus open surgery for suspected appendicitis. Cochrane Database Syst Rev. 2010;6(10):CD001546.

2. Keus F, de Jong JA, Gooszen HG, et al. Laparoscopic versus open cholecystectomy for patients with symptomaticcholecystolithiasis. Cochrane Database Syst Rev. 2006;18(4):CD006231.

3. Mukund Bahadur KC, Murray PJ. Cell phone short messaging service (SMS) for HIV/AIDS in South Africa: A literature review. Stud Health Technol Inform. 2010;160(Pt 1):530-534.

4. Shet A, de Costa A. India calling: Harnessing the promise of mobile phones for HIV healthcare. Trop Med Int Health. 2011;16(2):214-216.

5. Lee YG, Jeong WS, Yoon G. Smartphone-based mobile health monitoring. Telemed J E Health. 2012;18(8):585-590.

6. McNulty JP, Ryan JT, Evanoff MG, et al. Flexible image evaluation: iPad versus secondary-class monitors for review of MR spinal emergency cases, a comparative study. Acad Radiol. 2012;19(8):1023-1028.

7. Quarterly Annual Statistics. National Telecommunications Commission (CONATEL). Ministry of Popular Power for Communication and Information. 2015.

8. Garside J. More mobile devices than people within five years. 2012;2006$08-10$.

9. Ackerman MJ, Filart R, Burgess LP, et al. Developing nextgeneration telehealth tools and technologies: Patients, systems, and data perspectives. Telemed J E Health. 2010;16(1):93-95.

10. Thomale UW, Knitter T, Schaumann A, et al. Smartphoneassisted guide for the placement of ventricular catheters. Childs Nerv Syst. 2013;29(1):131-139.

11. Vodopivec-Jamsek V, de Jongh T, Gurol-Urganci I, et al. Mobile phone messaging for preventive health care. Cochrane Database Syst Rev. 2012;12:CD007457.

12. WHO Global Report. 2014-01-19. mhealth new horizons for health using mobile technologies. Geneva: World Health Organization; 2014. p. $1-112$. 
13. Blaya JA, Fraser HS, Holt B. E-health technologies show promise in developing countries. Health Aff (Millwood). 2010;29(2):244-251.

14. Karippacheril JG, Le Cong M. Videolaryngoscopy using an Android smartphone: A direct digital technique. Indian J Anaesth. 2016;60(2):143-145.

15. Vera-Domínguez J, Otero-Hernández LE, Turrubiates-Calcáneo EM. Telemedicine and teleotolaryngology: A feasible project for the Servicio de Sanidad Militar in Mexico. Rev Sanid Milit Mex. 2010;64(2):79-83.

16. Leiby C. Purchasing Insight: Endoscopic Surgery Video System. MD BuyLine 2016.

17. George A, Prince M, Coulson C. The 'endoscope-i': a mobile solution for endoscopy in otolaryngology. Clin Otolaryngol. 2013;38(1):104-106.

18. Oeldorf-Hirsch A, Donner J, Cutrell E. How bad is good enough? Exploring mobile video quality trade-offs for bandwidth constrained consumers. In: Proceedings of the Seventh Nordic Conference on HumanComputer Interaction: Making Sense Through Design. New York, NY: Association for Computing Machinery; 2012. p. 49-58.

19. Hsieh CH, Tsai HH, Yin JW, et al. Teleconsultation with the mobile camera-phone in digital soft-tissue injury: a feasibility study. Plast Reconstr Surg. 2004;114(7):1776-1782.

20. Pimmer C, Mateescu M, Zahn C, Genewein U. Smartphones as multimodal communication devices to facilitate clinical knowledge processes: randomized controlled trial. J Med Internet Res. 2013;15(11):263.
21. 1951 USAF resolution test chart. In Wikipedia, The Free Encyclopedia. 2016;09:54

22. Munsell color system. In Wikipedia, The Free Encyclopedia. 2016;05:48

23. Winkler S, Mohandas P. The evolution of video quality measurement: from PSNR to hybrid metrics. IEEE Trans Broadcast. 2008;54(3):660668.

24. Chikkerur S, Sundaram V, Reisslein M, Karam LJ. Objective video quality assessment methods: a classification, review, and performance comparison. IEEE Trans Broadcast. 2011;57(2):165-182.

25. Cermak GW. Subjective video quality as a function of bit rate frame rate, packet loss, and codec. In: 2009 International Workshop on Quality of Multimedia Experience, QoMEx 2009. Piscataway, NJ: IEEE; 2009. p.4 $1-46$

26. Liu H, Akiki S, Barrowman N, et al. Mobile Endoscopy vs Video Tower: A Prospective Comparison of Video Quality and Diagnostic Accuracy. Otolaryngol Head Neck Surg. 2016;155(4):575-580.

27. Sohn W, Shreim S, Yoon R. et al. Endockscope: Using Mobile Technology to Create Global Point of Service Endoscopy. J Endourol. 2013;27(9):1154-1160. 